\title{
Esculetin exerts anti-proliferative effects against non-small-cell lung carcinoma by suppressing specificity protein 1 in vitro
}

Ra H. Lee ${ }^{1, \star}$, Young-Joo Jeon ${ }^{1,2, \star}$, Jin H. Cho ${ }^{1, \star}$, Jeong-Yun Jang ${ }^{1}$, Il-Keun Kong ${ }^{3}$, Seok-Ho $\mathrm{Kim}^{4}$, MinSeok S. Kim ${ }^{5}$, Hak-Jae Chung ${ }^{6}$, Keon B. Oh ${ }^{6}$, Seon-Min Park ${ }^{7}$, Jae-Cheon Shin ${ }^{7}$, Jae-Min Seo ${ }^{8}$, Sungho Ko ${ }^{9}$, Jung-Hyun Shim ${ }^{10,11}$ and Jung-Il Chae ${ }^{1}$

1 Department of Dental Pharmacology, School of Dentistry, BK21 Plus, Chonbuk National University, Jeonju, Republic of Korea

2 LMO Technology Development Team, Converging Research Division, National marine biodiversity institute of Korea, Republic of Korea

3 Department of Animal Science, Division of Applied Life Science, Gyeongsang National University, Jinju 660-701, Gyeongsangnam-do, Republic of Korea

4 Aging Research Institute, Korea Research Institute of Bioscience \& BioTechnology, 125 Gwahak-ro, Yuseong-gu, Daejeon, Republic of Korea

5 Department of Biomedical Engineering, Konyang University, 158 Gwanjeodong-ro, Seo-gu, Daejeon, Republic of Korea

6 Animal Biotechnology Division, National Institute of Animal Science, Rural Development Administration, Suwon, Gyeonggi-Do, South Korea

7 Pohang Center for Evaluation of Biomaterials, Pohang, Gyeongbuk, Republic of Korea

8 Department of Prosthodontics, School of Dentistry and Institute of Oral Bio-Science and Research Institute of Clinical Medicine, Chonbuk National University, Jeonju 561-756, Republic of Korea

9 Department of Biotechnology, CHA University, Seongnam, Gyeonggi-do 463-836, Republic of Korea

${ }^{10}$ Department of Pharmacy, College of Pharmacy and Natural Medicine Research Institute, Mokpo National University, Jeonnam 58554, Republic of Korea

${ }^{11}$ The China -US (Henan) Hormel Cancer Institute, Zhengzhou, Henan, China

\begin{abstract}
Esculetin, a coumarin derivative, is a phenolic compound isolated from Artemisia capillaris, Citrus limonia, and Euphorbia lathyris. Although it has been reported to have anti-inflammatory, anti-oxidant, and anti-proliferative activities in several human cancers, its anti-proliferative activity against non-small-cell lung carcinoma (NSCLC) and the molecular mechanisms involved have not been adequately elucidated. In this study, we used two NSCLC cell lines (NCI-H358 and NCI-H1299) to investigate the anti-proliferative activity and apoptotic effect of esculetin. Our data showed that esculetin-treated cells exhibited reduced proliferation and apoptotic cell morphologies. Intriguingly, the transcription factor specificity protein 1 (Sp1) was significantly suppressed by esculetin in a dose- and time-dependent manner. Furthermore, the levels of p27 and p21, two key regulators of the cell cycle, were up-regulated by the esculetin-mediated down-regulation of Sp1; the level of a third cell-cycle regulator, survivin, was decreased, resulting in caspase-dependent apoptosis. Therefore, we conclude that esculetin could be a potent anti-proliferative agent in patients with NSCLC.
\end{abstract}

Key words: Apoptosis - Esculetin — Non-small-cell lung carcinoma - Specificity protein 1

\footnotetext{
* These authors contributed equally to this work

Correspondence to: Sungho Ko, Department of Biotechnology, CHA University, Seongnam, Gyeonggi-do 463-836, Republic of Korea E-mail: shko7@cha.ac.kr

Jung-Hyun Shim, Department of Pharmacy, College of Pharmacy and Natural Medicine Research Institute, Mokpo National University, Jeonnam 58554, Republic of Korea; and the China -US (Henan) Hormel Cancer Institute, Zhengzhou, Henan, China E-mail: s1004jh@gmail.com

Jung-Il Chae, Department of Dental Pharmacology, School of Dentistry and Institute of Dental Bioscience, BK21 plus, Chonbuk National University, Jeonju 651-756, Republic of Korea

E-mail: jichae@jbnu.ac.kr
} 


\section{Introduction}

Lung cancer is a major cause of cancer death worldwide, accounting for about one million deaths each year. Its incidence is strongly associated with cigarette smoking, with approximately $90 \%$ of lung cancers being generated by tobacco use (Jemal et al. 2011). Lung cancer is categorized into two morphologic groups: small-cell lung carcinoma and non-small-cell lung carcinoma (NSCLC). About 85\% of the patients with lung cancer have NSCLC, and about half this group present with advanced metastatic disease (stage IV; Molina et al. 2008). Furthermore, NSCLC is mostly an insidious disease, with no detectable symptoms until it has spread too far to be cured. When symptoms do develop, they may be due to the lung tumor itself or its effects on tissues outside the lung or to the spread of cancerous cells to other sites, including the lymph nodes, adrenal gland, bone, ovary, pancreas, liver, and brain (DeVita et al. 2005). The major treatment for NSCLC is surgery combined with radiation and chemotherapy, but many patients are not eligible for surgical treatment (Saintigny and Burger 2012). Chemotherapy by itself has effectively cured NSCLC. Recent attempts to develop effective strategies to prevent NSCLC have focused on dietary agents, including coumarin derivatives (Lopez-Gonzalez et al. 2004).

Strategies to minimize the side effects of cancer have recently involved the use of natural products (Mateen et al. (2013). Esculetin (6,7-dihydroxycoumarin) is a coumarin derivative produced by various plant materials (e.g., Artemisia capillaris, Citrus limonia, and Euphorbia lathyris) that are traditionally used as folk medicines (Chang et al. 1996; Masamoto et al. 2003). Interestingly, esculetin has been found to have a variety of biological activities, including anti-oxidant, anti-inflammatory, anti-proliferation, and anti-edematous effects (Fylaktakidou et al. 2004; Yun et al. 2011; Lee et al. 2013). However, the molecular mechanisms in esculetin's potential anti-proliferative activity in NSCLC have not been clarified.

The transcription factor specificity protein 1 (Sp1) expressed in mammalian cells is a member of the specificity protein/Krüppel-like factor transcription factor family, which interacts with the GC-rich regions and binds to DNA through three $\mathrm{Cys}^{2} / \mathrm{His}^{2}$-type zinc fingers in the C-terminal domain (Suske 1999; Li and Davie 2010). Sp1 target genes are mainly associated with cell proliferation, cell cycle and arrest, apoptosis, and tumorigenesis (Zhang et al. 2005; Wang et al. 2009; Kong et al. 2010; Nam et al. 2012). Furthermore, Sp1 is often over-expressed in several types of cancer cells, such as in gastric, thyroid, lung, and colorectal cancers, but not in normal cells (Chiefari et al. 2002; Wang et al. 2003; Chuang et al. 2009; Colon et al. 2011; Pathi et al. 2012). For these reasons, ways to inhibit Sp1 have been explored for the prevention or treatment of human cancers. Thus, Sp1 suppression may be a logical approach to treating cancer.

In this regard, to verify the therapeutic potential $S p 1$, this study examines whether esculetin regulates Sp1 target proteins can induce apoptosis by suppressing the level of Sp1 in NCI-H358 and NCI-H1299 cells.

\section{Materials and Methods}

\section{Cell culture}

Human NCI-H358 and NCI-H1299 cell lines acquired from the American Type Culture Collection (Manassas, VA, USA) were grown in RPMI-1640 (Welgene, Deagu, Korea), supplemented with $10 \%$ fetal bovine serum (FBS) and $100 \mathrm{U} / \mathrm{ml}$ each of penicillin and streptomycin (Gibco, Grand Island, NY, USA) in appropriate concentrations at $37^{\circ} \mathrm{C}$ with $5 \%$ $\mathrm{CO}_{2}$ in a fully humidified atmosphere.

\section{Cell viability assay}

The effect of esculetin on cell viability was estimated using a MTS (3-(4,5-dimethylthiazol-2-yl)-5-(3carboxymethoxyphenyl)-2-(4-sulfophenyl)-2H-tetrazolium) assay kit (Promega, Madison, WI, USA). NCI-H358 $\left(3.5 \times 10^{3}\right)$ and NCI-H1299 $\left(2.5 \times 10^{3}\right)$ cells were seeded overnight on a 96-well microtiter plate and were then treated with esculetin for 24 or $48 \mathrm{~h}$. The absorbance was measured using an Absorbance Microplate Reader (BioTek, Winooski, VT, USA) at $490 \mathrm{~nm}$, and each of the measurements was carried out in triplicate. The viability of esculetin-treated cells was represented as a percentage after being normalized to the viability of untreated control cells.

\section{DAPI staining}

The nuclear condensation and fragmentation levels were observed via nucleic acid staining with DAPI (4'-6-diamidino2-phenylindole). The NCI-H358 and NCI-H1299 cells were treated with various concentrations of esculetin and were harvested via trypsinization, washed with ice-cold phosphate buffered saline (PBS), and then fixed in $100 \%$ methanol at room temperature for $20 \mathrm{~min}$. The cells were spread on a slide and stained with a DAPI solution (Sigma-Aldrich, St. Louis, MO, USA). Fluorescence images were then taken using a confocal laser microscope (FluoView FV10i, Olympus Corp., Tokyo, Japan).

\section{Annexin V/propodium iodide (PI) staining}

Cells were seeded onto a $100-\mathrm{mm}^{2}$ dish containing NCIH358 $\left(3 \times 10^{6}\right)$ and NCI-H1299 $\left(2 \times 10^{6}\right)$ cells and then 
treated for $48 \mathrm{~h}$ with various concentrations of esculetin ( 0 , 50,100 and $150 \mu \mathrm{g} / \mathrm{ml}$ ). Both adherent and floating cells were harvested and washed once with PBS. To detect apoptosis, we incubated the cells with Annexin V/PI for 15 min at room temperature in the dark. Apoptotic and necrotic cells were analyzed by flow cytometry (BD FACSVerse, BD Biosciences, Oxford, UK) using the FITC Annexin V Apoptosis Detection Kit 1 (BD Biosciences). The experiment was conducted independently in triplicate.

\section{Immunocytochemistry analysis}

The cells were seeded on sterilized glass coverslips in fourwell tissue culture plates for $24 \mathrm{~h}$ and incubated with various concentrations of esculetin $(0,50,100$ and $150 \mu \mathrm{g} / \mathrm{ml})$ for $48 \mathrm{~h}$. The cells were fixed/permeabilized with cytotoxic solution (BD Biosciences) for $20 \mathrm{~min}$ at $4^{\circ} \mathrm{C}$. After washing twice with PBS, the cells were incubated with anti-Sp1 and in $1 \% \mathrm{BSA}$ at $4^{\circ} \mathrm{C}$ overnight. The cells were again washed with PBS and were subsequently incubated with Alexa Fluor
488 conjugated anti-rabbit IgG secondary antibodies (1:400 dilution) (Life Technologies, Carlsbad, CA, USA) in 1\% bovine serum albumin (BSA) for $1 \mathrm{~h}$ at room temperature. Cell nuclei were stained with DAPI. Finally, the stained cells were mounted using a solution that contained $10 \%$ glycerol and were then observed under a laser microscope (Olympus).

\section{Western blot analysis}

Protein expression levels were analyzed by means of Western blotting. After the NCI-H358 and NCI-H1299 cells were treated with esculetin, they were washed with ice-cold PBS and then lyzed in ice-cold Mammalian Protein Extraction Reagent (M-PER, Thermo Scientific, Rockford, IL, USA) containing a protease inhibitor cocktail (Roche, Basel, Switzerland). The soluble fraction of the cell lysates was isolated by centrifugation at $13,000 \times g$ for $15 \mathrm{~min}$ in a microfuge. The BCA Protein Assay Kit (Thermo Scientific) was used to measure the protein concentration in the supernatants, and equal amounts of protein samples were separated by $10 \%$
A<smiles>O=c1ccc2cc(O)c(O)cc2o1</smiles>

Esculetin
B

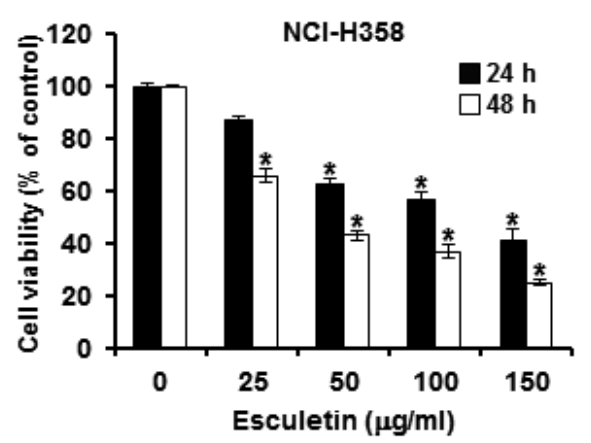

$\mathrm{NCl}-\mathrm{H} 1299$

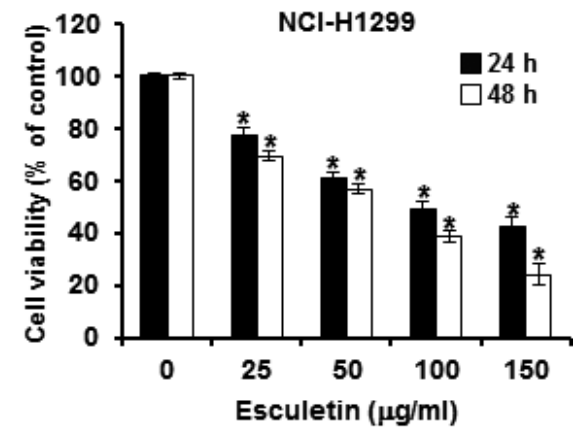

C

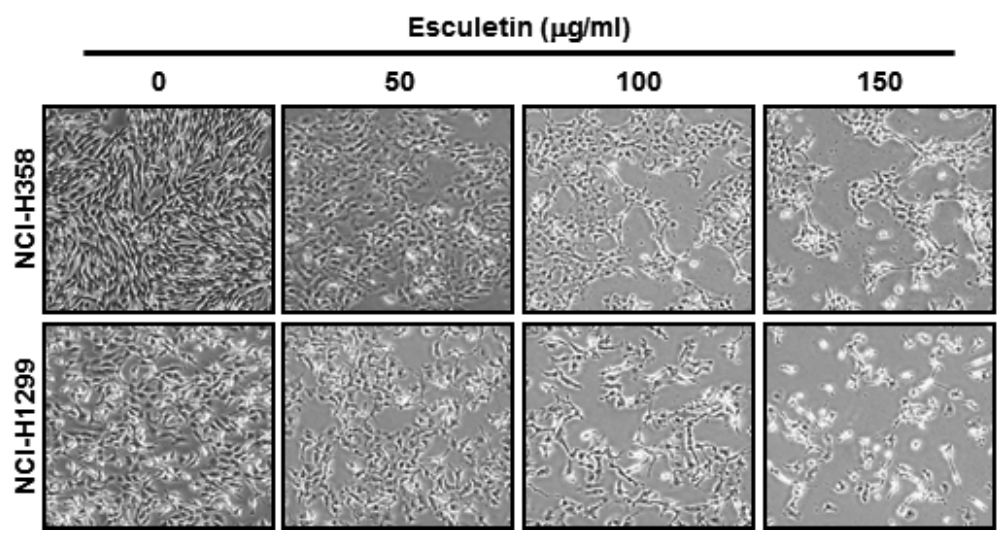

Figure 1. The effect of esculetin on cell viability in NSCLC cells. A. Chemical structure of esculetin. B. The NCI-H358 and NCI-H1299 cells were treated with different concentrations of esculetin $(0,50,100$ and $150 \mu \mathrm{g} / \mathrm{ml})$ for 24 and $48 \mathrm{~h}$, and cell viability was assessed using the MTS assay. The asterisk indicates a significant difference relative to negative control (untreated) cells $\left({ }^{*} p<0.05\right)$. C. Cellular morphological changes in NCI-H358 and NCI-H1299 cells with or without esculetin treatment (in concentrations of $0,50,100$ and $150 \mu \mathrm{g} / \mathrm{ml})$ for $48 \mathrm{~h}($ magnification $\times 40)$. 
or $12 \%$ SDS-polyacrylamide gel electrophoresis and were then transferred to polyvinylidene difluoride membranes (Millipore, Billerica, MA, USA), which were blocked for $30 \mathrm{~min}$ at room temperature with $5 \%(\mathrm{v} / \mathrm{v})$ skim milk in TBS buffer containing $0.1 \%$ Tween-20. The samples were then incubated with primary antibodies overnight at $4^{\circ} \mathrm{C}$. The membranes were washed five times for $10 \mathrm{~min}$ with TBS-T and were incubated with horseradish peroxidaseconjugated anti-mouse IgG or anti-rabbit IgG or anti-goat IgG antibodies (Santa Cruz Biotechnology, Santa Cruz, CA, USA). The membranes were then washed five times for 10 min with TBS-T, and the chemiluminescence signals were enhanced using a Pierce ECL Western Blotting Substrate (Thermo Scientific) and detected using ImageQuant Las4000 Mini (GE Healthcare Life Sciences, Buckinghamshire, UK).

\section{Statistical analysis}

Results were presented as means \pm standard deviation (SD) of triplicate independent experiments. Statistical significance was assessed using a Student's $t$-test. A value $p<0.05$, as compared with the non-treated control, was considered statistically significant.

\section{Results}

\section{Esculetin inhibits cell viability of NSCLC cells}

The structure of esculetin is shown in Fig. 1A. The effects of esculetin on cell proliferation in the NCI-H358 and NCIH1299 cells lines were verified by MTS assay. As shown in
A

\section{Esculetin $(\mu \mathrm{g} / \mathrm{ml})$}
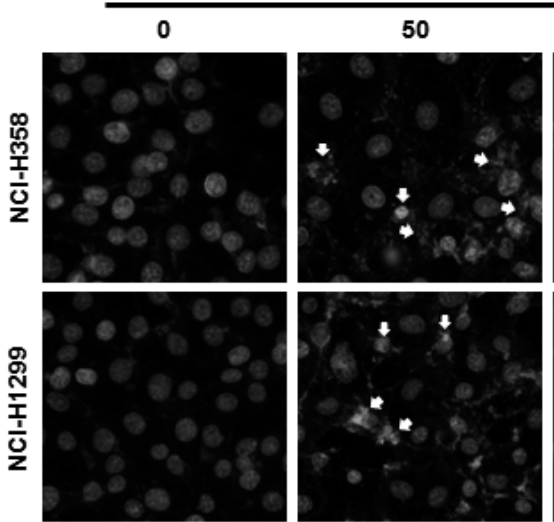

C

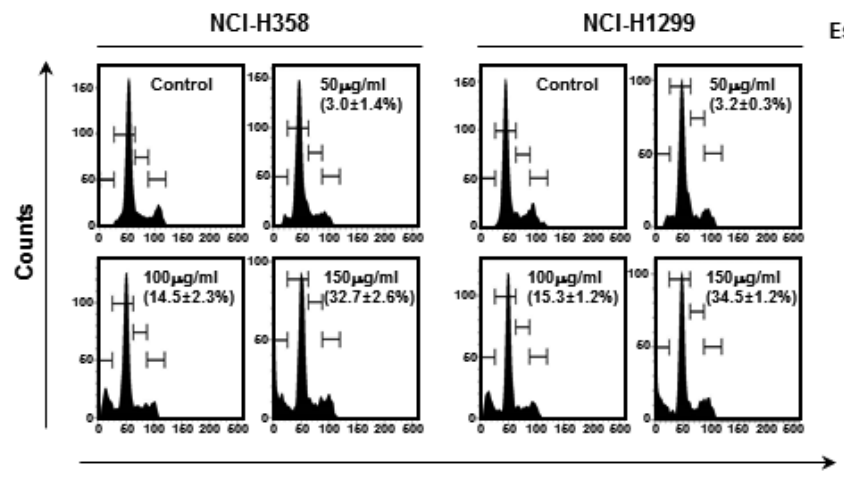

Propidium lodide-A
B
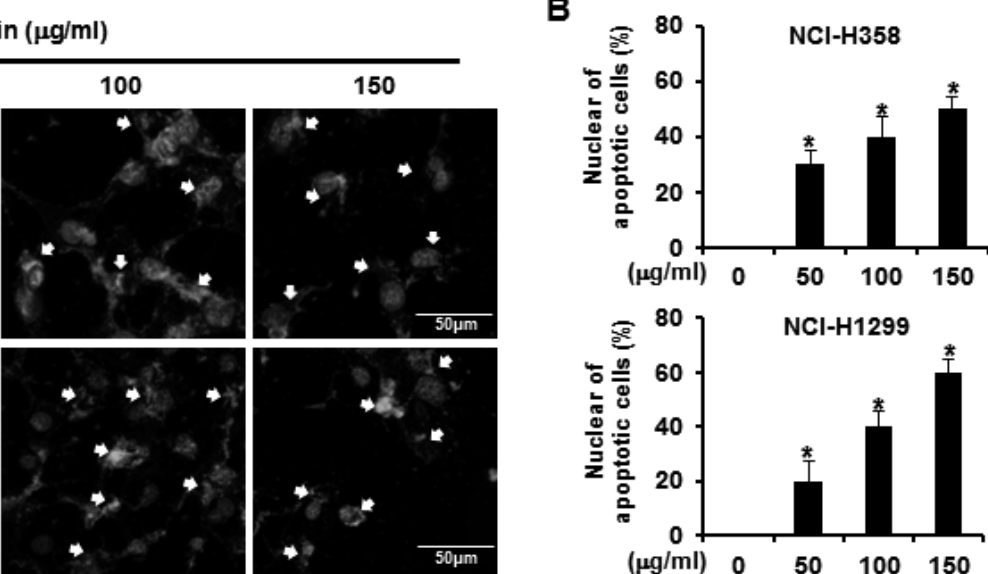

D
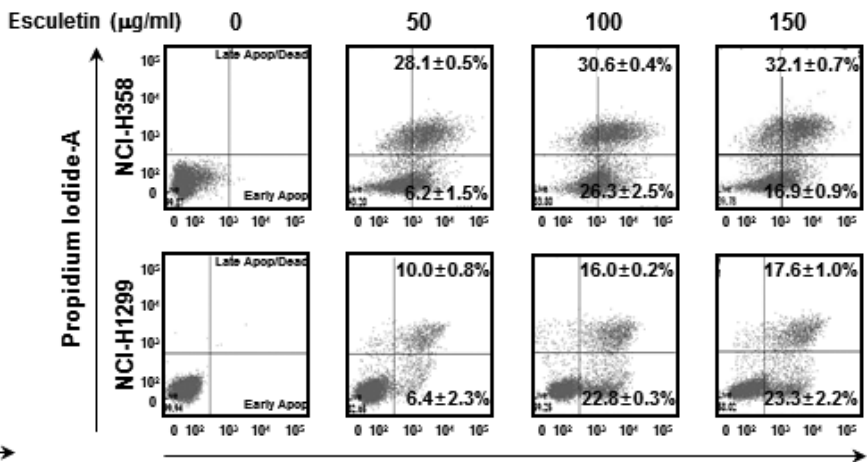

Annexin V FITC-A

Figure 2. The effect of esculetin on induction of apoptosis in NSCLC cells. The NCI-H358 and NCI-H1299 cells were incubated with different concentrations of esculetin $(0,50,100$ and $150 \mu \mathrm{g} / \mathrm{ml})$ for $48 \mathrm{~h}$. A. Fluorescence microscopic images of DAPI staining. Scale bar $=50 \mu \mathrm{m}$. B. DNA fragmentation and nuclear condensation were quantified, and data represent mean percentages $\pm \mathrm{SD}\left({ }^{*} p<0.05\right)$. C. NCI-H358 and NCI-H1299 cells were treated with 50,100 and $150 \mu \mathrm{g} / \mathrm{ml}$ esculetin or DMSO (vehicle), and the cells were washed, fixed, stained with propidium iodide (PI) and analyzed for DNA content by flow cytometry $48 \mathrm{~h}$ after treatment. The ratio of apoptotic cells was measured by flow cytometry after PI staining. D. Quantitative detection of Annexin V/7-AAD positive cells was performed with the Muse Cell Analyzer. Cells stained with Annexin $\mathrm{V}$ only were defined as early apoptotic (lower right); Annexin V and 7-AAD double-stained cells were defined as late apoptotic (upper right). 
Fig. 1B, the efficiency of esculetin in altering the viability of NCI-H358 and NCI-H1299 cells was assayed after 24 and $48 \mathrm{~h}$ of incubation in media containing esculetin at different concentrations $(25,50,100$ and $150 \mu \mathrm{g} / \mathrm{ml})$. The $\mathrm{IC}_{50}$ value of esculetin at $48 \mathrm{~h}$ was estimated to be $58.1 \mu \mathrm{g} / \mathrm{ml}$ in the NCI$\mathrm{H} 358$ and $43.9 \mu \mathrm{g} / \mathrm{ml}$ in the NCI-H1299 cells. Thus, esculetin decreased cell proliferation of NCI-H358 and NCI-H1299 cells in a dose- and time-dependent manner for 24 and $48 \mathrm{~h}$. To investigate morphological changes, NCI-H358 and NCIH1299 cells were treated with three different concentrations of esculetin $(50,100$ and $150 \mu \mathrm{g} / \mathrm{ml})$ for $48 \mathrm{~h}$. The apoptotic features included cell rounding, cytoplasmic blebbing, and irregularities in a dose-dependent manner (Fig. 1C). These results indicate that esculetin inhibited the growth of human NSCLC cells.

\section{Esculetin induces apoptosis of NSCLC cells}

To determine whether esculetin induced apoptosis in the two NSCLC cell lines, we carried out confocal laser microscopic analysis of the esculetin-treated NCI-H358 and NCI-H1299 cells to visualize the apoptotic morphological changes using DAPI staining. The results indicated the presence of nuclear condensation and perinuclear apoptotic bodies in the NCI-H358 and NCI-H1299 cells, after esculetin treatment at concentrations of $0,50,100$ and $150 \mu \mathrm{g} / \mathrm{ml}$ for $48 \mathrm{~h}$ (Fig. 2A, B). The cell cycle distribution was analyzed through the FACS analysis. As shown in the graphs of Fig. $2 \mathrm{C}$, there was significant increase in the number of sub-G1 cells in NCI-H358 cells: $3.0 \pm 1.4,14.5 \pm 2.3$ and $32.7 \pm$ $2.6 \%$ in the presence of 50,100 and $150 \mu \mathrm{g} / \mathrm{ml}$ of esculetin,
A

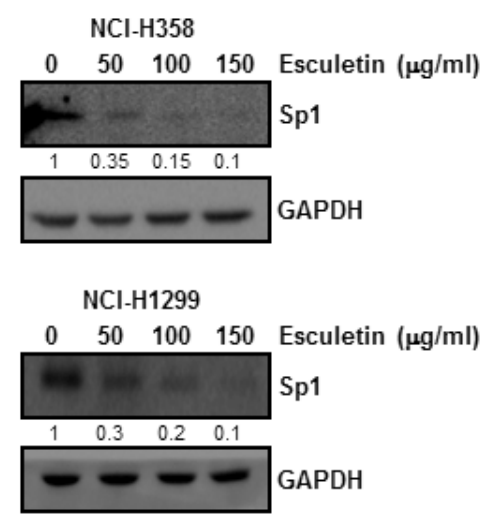

B

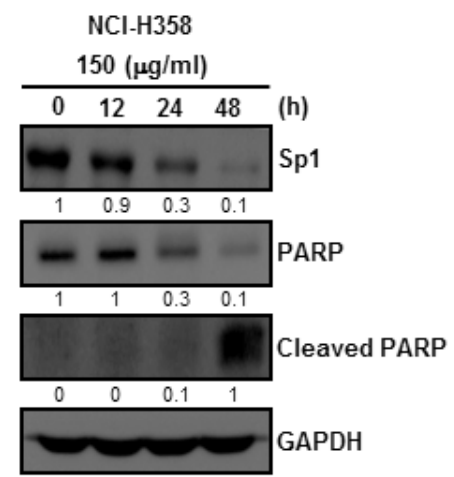

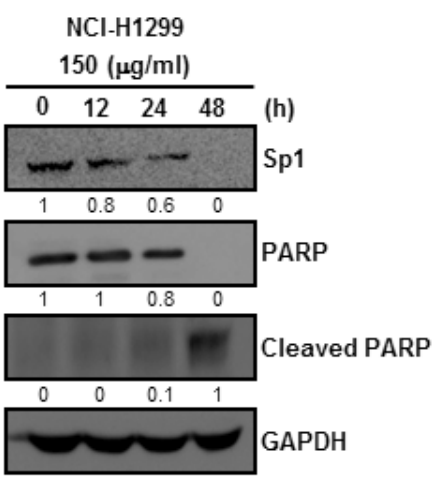

C

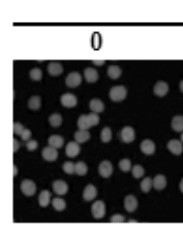

$\mathrm{NCl}-\mathrm{H} 358$

50
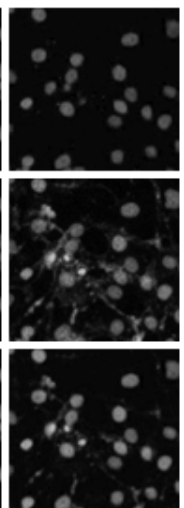
100
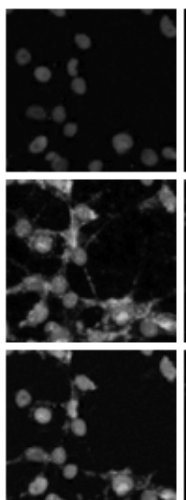

150

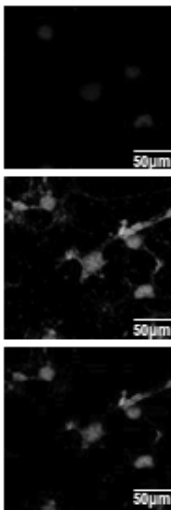

$\mathrm{NCl}-\mathrm{H} 1299$

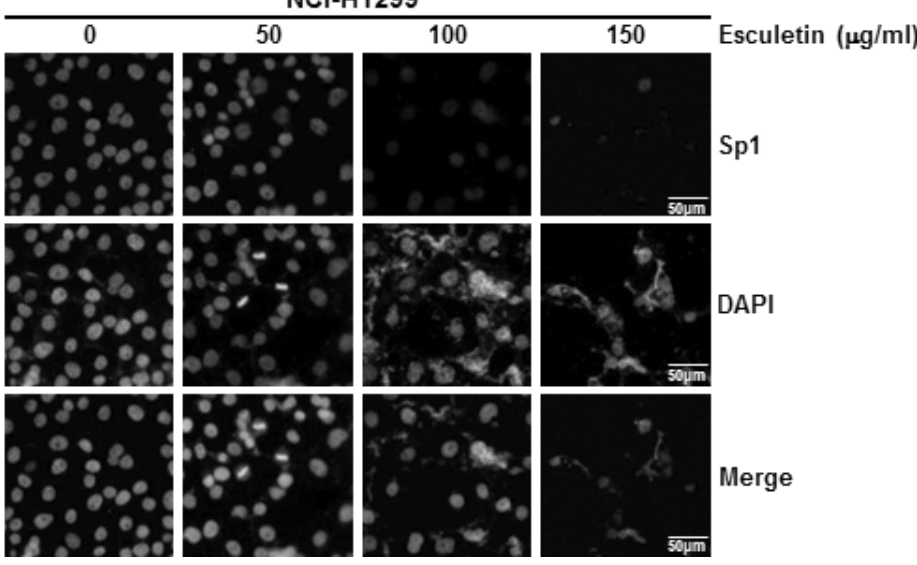

Figure 3. Effect of esculetin on the level of Sp1 expression in NSCLC cells. A. NCI-H358 and NCI-H1299 cells were treated with different concentrations of esculetin $(0,50,100$ and $150 \mu \mathrm{g} / \mathrm{ml})$ for $48 \mathrm{~h}$. The cell lysates were separated by SDS-PAGE, and the membranes were then transferred from SDS-PAGE gels subjected to Western blot analysis to detect Sp1. An equal loading protein was confirmed using GAPDH. B. The NCI-H358 and NCI-H1299 cells were treated with $150 \mu \mathrm{g} / \mathrm{ml}$ of esculetin for $0,12,24$ and $48 \mathrm{~h}$ and were then evaluated to determine the expression levels of Spl and PARP. Equal loading protein was confirmed using GAPDH. C. Immunofluorescence microscopic analysis of NCI-H358 and NCI-H1299 cells treated with different concentrations of esculetin (0, 50, $100 \mathrm{and} 150 \mu \mathrm{g} / \mathrm{ml})$ for $48 \mathrm{~h}$, after which the cells were immunostained with anti-Sp1. Signals were detected with Alexa Fluor 488-conjugated anti-rabbit secondary antibody. DAPI was used for nuclear staining. Scale bar $=50 \mu \mathrm{m}$. 
respectively, in comparison to untreated control cells. An increase in the number of sub-G1 cells was also observed in NCI-H1299 cells: $3.2 \pm 0.3,15.3 \pm 1.2$ and $34.5 \pm 1.2 \%$ in the presence of 50,100 and $150 \mu \mathrm{g} / \mathrm{ml}$ of esculetin, respectively, in comparison to untreated control cells. Cells stained with Annexin $\mathrm{V}$ only were defined as early apoptotic and Annexin V (lower right) and 7-AAD double-stained cells were defined as late apoptotic (upper right). Esculetin displayed marked effects to induce apoptosis of NCI-H358 and NCI-H1299 cells in a dose-dependent manner (Fig. 2D). Treatment of the NCI-H358 cells with 50, 100 and $150 \mu \mathrm{g} / \mathrm{ml}$ of esculetin for $48 \mathrm{~h}$ resulted in $6.2 \pm 1.5,26.3$ \pm 2.5 and $16.9 \pm 0.9 \%$ of early apoptotic cells (lower right) and $28.1 \pm 0.5,30.6 \pm 0.4$ and $32.1 \pm 0.7 \%$ of late apoptotic cells (upper right), respectively. Similarly, treatment of NCIH1299 cells with esculetin also led to $6.4 \pm 2.3,22.8 \pm 0.3$ and $23.3 \pm 2.2 \%$ of early apoptotic cells (lower right) and $10.0 \pm 0.8,16.0 \pm 0.2$ and $17.6 \pm 1.0 \%$ of late apoptotic cells (upper right) at the same three concentrations as above, respectively. Apparently, esculetin-mediated apoptosis of NCI-H358 and NCI-H1299 cells, at least in part, contributed to its anti-proliferative effects.

\section{Esculetin suppresses expression of Sp1 in NSCLC cells}

Previous studies have shown that higher levels of transcription factor Sp1 expression were associated with human cancer development (Sankpal et al. 2011). Therefore, to examine Sp1 expression, NCI-H358 and NCI-H1299 cells were treated with different concentrations of esculetin ( 0 , 50, 100 and $150 \mu \mathrm{g} / \mathrm{ml}$ ) for $48 \mathrm{~h}$. Esculetin suppressed Sp1 expression levels in a dose-dependent manner (Fig. 3A). To further investigate the time-dependent expression levels of Sp1, we treated the cells with $150 \mu \mathrm{g} / \mathrm{ml}$ esculetin at four different times $(0,12,24$ and $48 \mathrm{~h})$. Esculetin also suppressed Sp1 expression levels in a time-dependent manner (Fig. 3B). Immunocytochemical analysis revealed decreased levels of Sp1 expression in the NCI-H358 and NCI-H1299 cells in a dose-dependent manner (Fig. 3C). Our results indicated that suppression of Sp1 by esculetin treatment leads to apoptotic cell death.

Esculetin regulated expression of cell-cycle and apoptosis-related proteins in NSCLC cells

Cyclin/cyclin-dependent kinase (CDK) complexes play an important role in cell-cycle regulation (Boxem et al. 1999; Boxem and van den Heuvel 2001). When we examined the expression levels of the cell-cycle regulatory proteins $\mathrm{p} 21$, p27, and survivin, we found that expression of p21 and p27 increased distinctively and that of survivin decreased after treatment with $150 \mu \mathrm{g} / \mathrm{ml}$ of esculetin for $48 \mathrm{~h}$ (Fig. 4). Furthermore, to determine whether treatment with esculetin regulated the expression of apoptosis-related proteins, we performed Western blot analyses. As shown in Fig. 5, activated caspase-3, poly (ADP-ribose) polymerase (PARP), and $\mathrm{Bcl}-\mathrm{xL}$ decreased in esculetin-treated NSCLC cells, whereas expression of the anti-apoptotic proteins Bax, cleaved PARP, and cleaved caspase- 3 increased. These data suggest that esculetin treatment of NSCLC decreases Sp1, resulting in growth arrest and apoptotic cell death.

\section{Discussion}

Since ancient times natural products have been widely used in clinical trials as a source of chemotherapeutic drugs (Cragg et al. (1997). Esculetin, a natural compound isolated from coumarin, is an attractive new therapeutic candidate for cancer prevention (Chang et al. 1996; Masamoto et al. 2003). Several potentially useful properties of esculetin have been reported such as its anti-oxidant, anti-inflammatory, and neuroprotective activities and its anti-proliferative, cell cycle arrest effects in oral cancer, human malignant melanoma, colon cancer, breast cancer, leukemia, cervical cancer, and human myeloma (Kloosterboer et al. 2004; Kim et al. 2008; Yang et al. 2010; Park et al. 2011; Subramaniam and Ellis 2013; Cho et al. 2015;
$\mathrm{NCl}-\mathrm{H} 358$

$0 \quad 50 \quad 100 \quad 150 \quad$ Esculetin $(\mu \mathrm{g} / \mathrm{ml})$

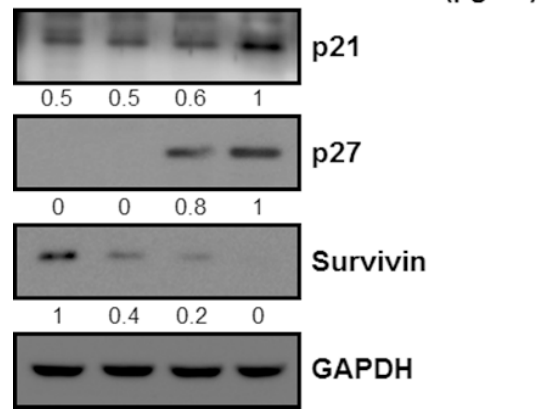

$\mathrm{NCl}-\mathrm{H} 1299$

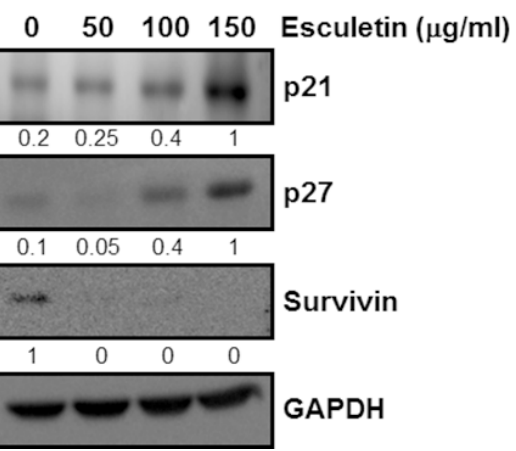

Figure 4. The effect of esculetin on the expression of cell cycle-related proteins in NSCLC cells. The NCI-H358 and NCIH1299 cells were incubated without or with different concentrations of esculetin $(0,50,100$ and $150 \mu \mathrm{g} / \mathrm{ml})$ for $48 \mathrm{~h}$. The cell lysates were determined using Western blot analysis with antibodies against p21, p27, and survivin. Equal loading protein was confirmed using GAPDH. Values were obtained by means of ImageJ densitometry. 


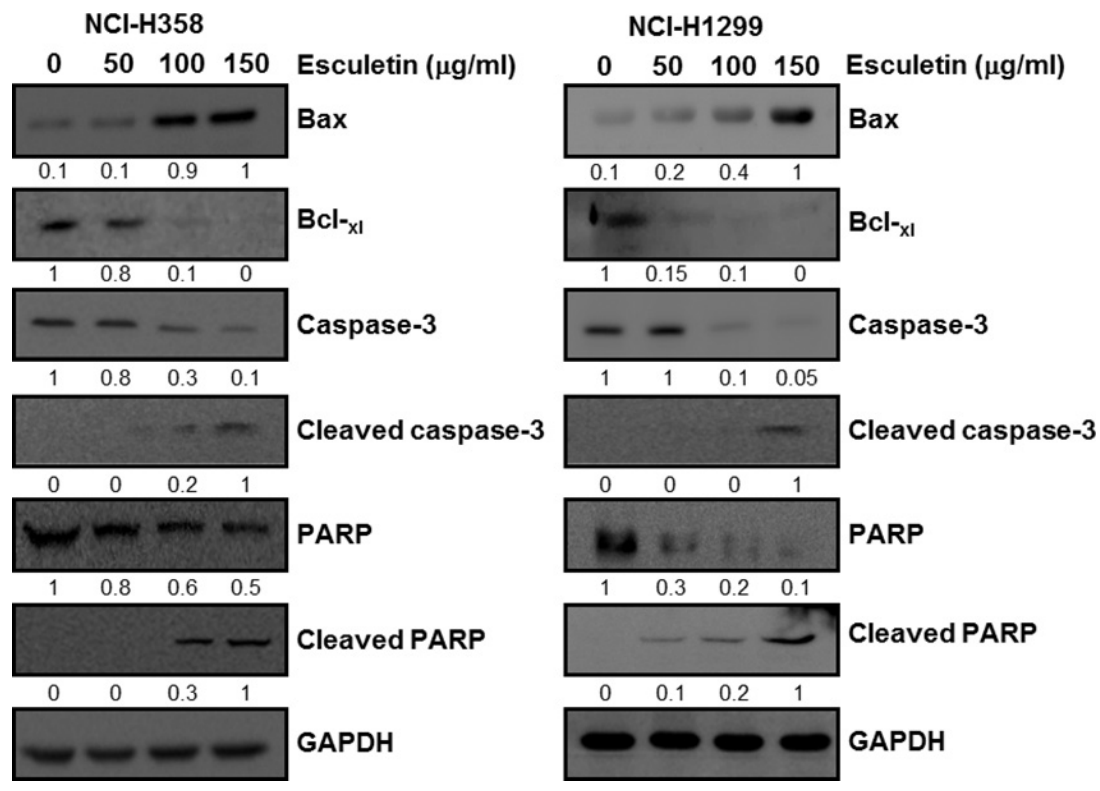

Figure 5. The effect of esculetin on the expression of apoptosis-related proteins in NSCLC cells. The NCI-H358 and NCI-H1299 cells were treated without or with different concentrations of esculetin $(0,50,100$ and $150 \mu \mathrm{g} / \mathrm{ml})$ for $48 \mathrm{~h}$. The cell lysates were evaluated by Western blot analysis using Bax, Bcl-xL, caspase-3, cleaved caspase-3, PARP, and cleaved PARP antibodies. Equal loading protein was confirmed using GAPDH. The values were measured using ImageJ densitometry.
Jeon et al. 2015). Despite numerous studies on a variety of cancer cells, the anti-proliferative effects of esculetin on NSCLC cells are not well understood.

In this study, we extensively explored the apoptotic effects of esculetin, at different times and concentrations, in two NSCLC cell lines, NCI-H358 and NCI-H1299. Most cases of NSCLC, a type of lung cancer, are diagnosed at an advanced stage when the disease is non-resectable. Our results showed that esculetin reduced the viability of NCI-H358 and NCI-H1299 cells, with a decrease in the size of the cells (morphologically seen as rounding) in a dose-dependent manner. DAPI staining and Annexin V cytometry revealed that esculetin induced significant apoptosis.

The transcription factor Sp1 is involved in a variety of cellular functions, including cell-cycle regulation, apoptosis, and differentiation. Many studies have reported that Sp1 is over-expressed in rapidly proliferating cancer cells, such as in human breast cancer, pancreatic cancer, colorectal cancer, gastric carcinoma, thyroid carcinoma, and hepatocellular carcinoma (Lietard et al. 1997; Chiefari et al. 2002; Wang et al. 2003; Abdelrahim et al. 2004; Hosoi et al. 2004; MertensTalcott et al. 2007). Sp1 appears to play a key role in tumor survival for numerous cancer cells and thus represents an attractive target for cancer treatment. Our data showed that esculetin induced apoptosis in NCI-H358 and NCI-H1299 cells by suppressing Sp1 expression levels in a dose- and time-dependent manner, confirming p21, p27, and survivin as Sp1 target proteins. Several human cancers frequently show down-regulation of p21 and p27, which are characterized as negative regulators of cell-cycle progression and G1-phase arrest that result from the interaction of cyclins/ CDK complexes (Sherr and Roberts 1999; Murray 2004).
Survivin is a member of the IAP (inhibitor of apoptosis) family and is a key regulator of mitosis and both G1 and G2 check points and apoptosis (Ambrosini et al. 1997; Altieri 2008). In this regard, our results indicate that esculetin increased the expression levels of p21 and p27 but decreased those of survivin in a dose-dependent manner. In agreement with these findings, esculetin reduced the expression levels of Bcl-xL but increased those of Bax, cleaved caspase-3, and cleaved PARP.

\section{Conclusions}

Esculetin inhibited NSCLC cell proliferation by suppressing Sp1, leading to the up-regulation of p21 and p27 and the down-regulation of survivin. Furthermore, esculetin regulated apoptosis-related proteins including Bax, Bcl-xL, caspase-3, cleaved caspase-3, PARP, and cleaved PARP. Esculetin thus exerted a potent anti-proliferative effect in NSCLC by triggering Sp1-mediated apoptotic signaling. Therefore, esculetin may be considered a drug or natural supplement candidate for the prevention of NSCLC.

Acknowledgement. This work was supported by the Next-Generation BioGreen 21 Program (PJ01116401) from Rural Development Administration, Republic of Korea.

\section{References}

Abdelrahim M., Smith R., 3rd, Burghardt R., Safe S. (2004): Role of Sp proteins in regulation of vascular endothelial growth factor 
expression and proliferation of pancreatic cancer cells. Cancer Res. 64, 6740-6749 https://doi.org/10.1158/0008-5472.CAN-04-0713

Altieri D. C. (2008): Survivin, cancer networks and pathwaydirected drug discovery. Nat. Rev. Cancer 8, 61-70 https://doi.org/10.1038/nrc2293

Ambrosini G., Adida C., Altieri D. C. (1997): A novel anti-apoptosis gene, survivin, expressed in cancer and lymphoma. Nat. Med. 3, 917-921 https://doi.org/10.1038/nm0897-917

Boxem M., Srinivasan D. G., van den Heuvel S. (1999): The Caenorhabditis elegans gene ncc-1 encodes a cdc2-related kinase required for $\mathrm{M}$ phase in meiotic and mitotic cell divisions, but not for S phase. Development 126, 2227-2239

Boxem M., van den Heuvel S. (2001): lin-35 Rb and cki-1 Cip/Kip cooperate in developmental regulation of G1 progression in C. elegans. Development 128, 4349-4359

Chang W. S., Lin C. C., Chuang S. C., Chiang H. C. (1996): Superoxide anion scavenging effect of coumarins. Am. J. Chin. Med. 24, 11-17 https://doi.org/10.1142/S0192415X96000037

Chiefari E., Brunetti A., Arturi F., Bidart J. M., Russo D., Schlumberger M., Filetti S. (2002): Increased expression of AP2 and Sp1 transcription factors in human thyroid tumors: a role in NIS expression regulation? BMC Cancer 2, 35 https://doi.org/10.1186/1471-2407-2-35

Cho J. H., Shin J. C., Cho J. J., Choi Y. H., Shim J. H., Chae J. I. (2015): Esculetin (6,7-dihydroxycoumarin): a potential cancer chemopreventive agent through suppression of Sp1 in oral squamous cancer cells. Int. J. Oncol. 46, 265-271

Chuang J. Y., Wu C. H., Lai M. D., Chang W. C., Hung J. J. (2009): Overexpression of Sp1 leads to p53-dependent apoptosis in cancer cells. Int. J. Cancer 125, 2066-2076 https://doi.org/10.1002/ijc.24563

Colon J., Basha M. R., Madero-Visbal R., Konduri S., Baker C. H., Herrera L. J., Safe S., Sheikh-Hamad D., Abudayyeh A., Alvarado B., Abdelrahim M. (2011): Tolfenamic acid decreases c-Met expression through Sp proteins degradation and inhibits lung cancer cells growth and tumor formation in orthotopic mice. Invest. New Drugs 29, 41-51

https://doi.org/10.1007/s10637-009-9331-8

Cragg G. M., Newman D. J., Snader K. M. (1997): Natural products in drug discovery and development. J. Nat. Prod. 60, $52-60$ https://doi.org/10.1021/np9604893

DeVita V. T., Hellman S., Rosenberg S. A. (2005): Cancer, Principles and Practice of Oncology. 7th edition, Lippincott Williams \& Wilkins, Philadelphia, PA

Fylaktakidou K. C., Hadjipavlou-Litina D. J., Litinas K. E., Nicolaides D. N. (2004): Natural and synthetic coumarin derivatives with anti-inflammatory/ antioxidant activities. Curr. Pharm. Des. 10, 3813-3833

https://doi.org/10.2174/1381612043382710

Hosoi Y., Watanabe T., Nakagawa K., Matsumoto Y., Enomoto A., Morita A., Nagawa H., Suzuki N. (2004): Up-regulation of DNA-dependent protein kinase activity and $\mathrm{Sp} 1$ in colorectal cancer. Int. J. Oncol. 25, 461-468 https://doi.org/10.3892/ijo.25.2.461
Jemal A., Bray F., Center M. M., Ferlay J., Ward E., Forman D. (2011): Global cancer statistics. CA Cancer J. Clin. 61, 69-90 https://doi.org/10.3322/caac.20107

Jeon Y. J., Jang J. Y., Shim J. H., Myung P. K., Chae J. I. (2015): Esculetin, a coumarin derivative, exhibits anti-proliferative and pro-apoptotic activity in G361 human malignant melanoma. J. Cancer Prev. 20, 106-112 https://doi.org/10.15430/JCP.2015.20.2.106

Kim S. H., Kang K. A., Zhang R., Piao M. J., Ko D. O., Wang Z. H., Chae S. W., Kang S. S., Lee K. H., Kang H. K., Kang H. W., Hyun J. W. (2008): Protective effect of esculetin against oxidative stress-induced cell damage via scavenging reactive oxygen species. Acta Pharmacol. Sin. 29, 1319-1326 https://doi.org/10.1111/j.1745-7254.2008.00878.x

Kloosterboer F. M., van Luxemburg-Heijs S. A., van Soest R. A., Barbui A. M., van Egmond H. M., Strijbosch M. P., Kester M. G., Marijt W. A., Goulmy E., Willemze R., Falkenburg J. H. (2004): Direct cloning of leukemia-reactive $\mathrm{T}$ cells from patients treated with donor lymphocyte infusion shows a relative dominance of hematopoiesis-restricted minor histocompatibility antigen HA-1 and HA-2 specific T cells. Leukemia 18, 798-808 https://doi.org/10.1038/sj.leu.2403297

Kong L. M., Liao C. G., Fei F., Guo X., Xing J. L., Chen Z. N. (2010): Transcription factor Sp1 regulates expression of cancerassociated molecule CD147 in human lung cancer. Cancer Sci. 101, 1463-1470 https://doi.org/10.1111/j.1349-7006.2010.01554.x

Lee S. Y., Lim T. G., Chen H., Jung S. K., Lee H. J., Lee M. H., Kim D. J., Shin A., Lee K. W., Bode A. M., Surh Y. J., Dong Z. (2013): Esculetin suppresses proliferation of human colon cancer cells by directly targeting beta-catenin. Cancer Prev. Res. (Phila) 6, 1356-1364 https://doi.org/10.1158/1940-6207.CAPR-13-0241

Li L., Davie J. R. (2010): The role of Sp1 and Sp3 in normal and cancer cell biology. Ann. Anat. 192, 275-283 https://doi.org/10.1016/j.aanat.2010.07.010

Lietard J., Musso O., Theret N., L'Helgoualc'h A., Campion J. P., Yamada Y., Clement B. (1997): Sp1-mediated transactivation of LamC1 promoter and coordinated expression of laminingamma1 and Sp1 in human hepatocellular carcinomas. Am. J. Pathol. 151, 1663-1672

Lopez-Gonzalez J. S., Prado-Garcia H., Aguilar-Cazares D., MolinaGuarneros J. A., Morales-Fuentes J., Mandoki J. J. (2004): Apoptosis and cell cycle disturbances induced by coumarin and 7-hydroxycoumarin on human lung carcinoma cell lines. Lung Cancer 43, 275-283

https://doi.org/10.1016/j.lungcan.2003.09.005

Masamoto Y., Ando H., Murata Y., Shimoishi Y., Tada M., Takahata K. (2003): Mushroom tyrosinase inhibitory activity of esculetin isolated from seeds of Euphorbia lathyris L. Biosci. Biotechnol. Biochem. 67, 631-634 https://doi.org/10.1271/bbb.67.631

Mateen S., Raina K., Agarwal R. (2013): Chemopreventive and anti-cancer efficacy of silibinin against growth and progression of lung cancer. Nutr. Cancer 65 (Suppl. 1), 3-11 https://doi.org/10.1080/01635581.2013.785004

Mertens-Talcott S. U., Chintharlapalli S., Li X., Safe S. (2007): The oncogenic microRNA-27a targets genes that regulate 
specificity protein transcription factors and the G2-M checkpoint in MDA-MB-231 breast cancer cells. Cancer Res. 67, $11001-11011$ https://doi.org/10.1158/0008-5472.CAN-07-2416

Molina J. R., Yang P., Cassivi S. D., Schild S. E., Adjei A. A. (2008): Non-small cell lung cancer: epidemiology, risk factors, treatment, and survivorship. Mayo Clin. Proc. 83, 584-594 https://doi.org/10.1016/S0025-6196(11)60735-0

Murray A. W. (2004): Recycling the cell cycle: cyclins revisited. Cell 116, 221-234 https://doi.org/10.1016/S0092-8674(03)01080-8

Nam E. H., Lee Y., Park Y. K., Lee J. W., Kim S. (2012): ZEB2 upregulates integrin alpha5 expression through cooperation with Sp1 to induce invasion during epithelial-mesenchymal transition of human cancer cells. Carcinogenesis 33, 563-571 https://doi.org/10.1093/carcin/bgs005

Park S. S., Park S. K., Lim J. H., Choi Y. H., Kim W. J., Moon S. K. (2011): Esculetin inhibits cell proliferation through the Ras/ ERK1/2 pathway in human colon cancer cells. Oncol. Rep. 25, 223-230

Pathi S., Jutooru I., Chadalapaka G., Nair V., Lee S. O., Safe S. (2012): Aspirin inhibits colon cancer cell and tumor growth and downregulates specificity protein (Sp) transcription factors. PLoS One 7, e48208 https://doi.org/10.1371/journal.pone.0048208

Saintigny P., Burger J. A. (2012): Recent advances in non-small cell lung cancer biology and clinical management. Discov. Med. 13, 287-297

Sankpal U. T., Goodison S., Abdelrahim M., Basha R. (2011): Targeting Sp1 transcription factors in prostate cancer therapy. Med. Chem. 7, 518-525 https://doi.org/10.2174/157340611796799203

Sherr C. J., Roberts J. M. (1999): CDK inhibitors: positive and negative regulators of G1-phase progression. Genes Dev. 13, $1501-1512$ https://doi.org/10.1101/gad.13.12.1501

Subramaniam S. R., Ellis E. M. (2013): Neuroprotective effects of umbelliferone and esculetin in a mouse model of Parkinson's disease. J. Neurosci. Res. 91, 453-461 https://doi.org/10.1002/jnr.23164

Suske G. (1999): The Sp-family of transcription factors. Gene 238, 291-300 https://doi.org/10.1016/S0378-1119(99)00357-1

Wang L., Wei D., Huang S., Peng Z., Le X., Wu T. T., Yao J., Ajani J., Xie K. (2003): Transcription factor Sp1 expression is a significant predictor of survival in human gastric cancer. Clin. Cancer Res. 9, 6371-6380

Wang S. A., Chuang J. Y., Yeh S. H., Wang Y. T., Liu Y. W., Chang W. C., Hung J. J. (2009): Heat shock protein 90 is important for Sp1 stability during mitosis. J. Mol. Biol. 387, 1106-1119 https://doi.org/10.1016/j.jmb.2009.02.040

Yang J., Xiao Y. L., He X. R., Qiu G. F., Hu X. M. (2010): Aesculetininduced apoptosis through a ROS-mediated mitochondrial dysfunction pathway in human cervical cancer cells. J. Asian Nat. Prod. Res. 12, 185-193 https://doi.org/10.1080/10286020903427336

Yun E. S., Park S. S., Shin H. C., Choi Y. H., Kim W. J., Moon S. K. (2011): p38 MAPK activation is required for esculetin-induced inhibition of vascular smooth muscle cells proliferation. Toxicol. In Vitro 25, 1335-1342 https://doi.org/10.1016/j.tiv.2011.05.001

Zhang J., Zhu Z. G., Ji J., Yuan F., Yu Y. Y., Liu B. Y., Lin Y. Z. (2005): Transcription factor $\mathrm{Sp} 1$ expression in gastric cancer and its relationship to long-term prognosis. World J. Gastroenterol. 11, 2213-2217 https://doi.org/10.3748/wjg.v11.i15.2213

Received: February 1, 2016

Final version accepted: June 10, 2016

First published online: November 30, 2016 